\title{
PEMETAAN ZONASI DAERAH RAWAN KEBAKARAN HUTAN DAN LAHAN DI KABUPATEN GOWA
}

\author{
(Zonation Mapping of Forest and Land Fire Areas in Gowa District) \\ Yuliandri Pualilin', Amir Tjoneng ${ }^{2}$, Abdullah $^{3}$ \\ Program Studi Magister Agroteknologi Pertanian \\ Pascasarjana Universitas Muslim Indonesia \\ Jl. Urip Sumoharjo No. 225 Makassar, 90232 Indonesia \\ Email :andri.pualillin@gmail.com
}

\begin{abstract}
Recent forest and land fires often occur, Gowa district has become a subscription to forest and land fires every time it enters the dry season. The research aims to determine the factors that influence forest and land fires, the distribution of areas prone to forest and land fires, compile / make zoning maps of areas prone to forest fires and in Gowa Regency. This research was conducted in Gowa Regency from April to July 2018. This study used software Arc GIS software to map areas prone to forest and land fires in Gowa Regency. The method used in this study is scoring and weighting by calculating the numerical index of the area prone to forest fires based on vegetation parameters, slope, slope direction (aspect), distance from the road, and distance from the settlement. The results of the study showed that Gowa Regency was dominated by classes of vulnerable forest fires and low land with medium to wide area of 68,777.43 hectares and 70,132.79 hectares. The causes of forest and land fires that have the potential to cause forest and land fires are land cover, slope and aspect. Areas prone to forest and land fires are the most potential to occur in Parangloe, Tombolopao, Bungaya, Bontolempangan, Biringbulu, Manuju and Pattallassang sub-districts with a total area of 1,735.42 ha or 0.96\% of the total area of Gowa Regency, while areas prone to forest fires and the smallest land occurred in Pallangga District with an area of $0.24 \mathrm{Ha}$.
\end{abstract}

Keywords: Zoning, forest and land fires, arcgis, Gowa district

\section{PENDAHULUAN}

Hutan merupakan sumberdaya alam yang tidak ternilai karena didalamnya terkandung keanekaragaman hayati sebagai sumber plasma nutfah, sumber hasil hutan kayu dan non-kayu, pengatur tata air, pencegah banjir dan erosi serta kesuburan tanah, perlindungan alam hayati untuk kepentingan ilmu pengetahuan, kebudayaan, rekreasi, pariwisata dan sebagainya

Di Kabupaten Gowa sering terjadi kebakaran lahan setiap memasuki musim kemarau. Menurut data Balai Pengendalian Perubahan Iklim dan Kebakaran Hutan dan Lahan Wilayah Sulawesi, pada tahun 2017 kebakaran hutan dan lahan di Kabupaten Gowa mencapai 7 kejadian dengan luas keseluruhan 9,3 ha dan jumlah titik panas sebanyak 25 titik panas (hotspot). Kerentanan terhadap kebakaran hutan, ini disebabkan oleh kondisi lahan yang didominasi lahan kering sehingga mudah terbakar. 
Salah satu kegiatan yang dilakukan dalam pencegahan kebakaran hutan dan lahan (Karhutla) yaitu pembuatan peta rawan Karhutla. Pengembangan pemetaan daerah rawan karhutla dapat dilakukan dengan bantuan teknologi penginderaan jarak jauh dan Sistem Informasi Geografis berdasarkan faktor yang mempengaruhi Karhutla, yaitu kondisi bahan bakar, kondisi klimatologi dan perilaku kebakaran (Rianawati, 2016).

Pemetaan daerah rawan kebakaran hutan dan lahan dapat dilakukan dengan dengan menggunakan teknologi Sistem Informasi Geografi (SIG) dan pemantauan titik panas (hotspot). Dengan menggunakan data titik api yang direkam secara kontinyu dan data spasial biofisik yang berpengaruh terhadap kejadian kebakaran hutan dan gambut, dapat dibuat peta kerawanan kebakaran di suatu daerah (Samsuri, Jaya, dan Syaufina, 2012, Widodo, 2014, Mukti dan Rushayati, 2016), Sehingga akan diperoleh daerah rawan kebakaran hutan dan lahan yang menjadi salah satu acuan dalam pemanfaatan ruang secara bijaksana bagi Pemerintah kabupaten Gowa.
Dalam upaya mengidentifikasi daerah rawan kebakaran hutan dan lahan untuk pencegahan kebakaran hutan dan lahan di Kabupaten Gowa, maka dilakukan kajian untuk menganalisis faktor-faktor yang mempengaruhi kebakaran hutan dan mengetahui sebaran daerah rawan kebakaran hutandan lahan serta menyusun/membuat pemetaan zonasi daerah yang rawan kebakaran hutan dan di Kabupaten Gowa.

\section{METODE PENELITIAN}

Peneitian ini dilaksanakan dari bulan April sampai dengan Juli 2018. Pelaksanaan kegiatan mulai dari pengumpulan data sampai penyusunan laporan dilakukan di Balai Pengendalian Perubahan Iklim dan Kebakaran Hutan dan Lahan Wilayah Sulawesi di Makassar.

\section{Prosedur Penelitian dan Analisa Data}

1. Pembobotan parameter

Pada tahap ini setiap peta tematik diolah dengan memasukkan kelas, faktor dan bobot pada tabel atributnya masingmasing sehingga dihasilkan Peta Kelas untuk setiap parameter. Tahapan pertama dari penelitian ini dilakukan berdasarkan Tabel 1. 
Yuliandri Pualilin : Pemetaan Zonasi Daerah Rawan Kebakaran Hutan dan Lahan di Kabupaten Gowa

Tabel 1. Sistem Pembobotan Parameter Penentu Tingkat Kerawanan Kebakaran Hutan

\begin{tabular}{|c|c|c|c|c|c|}
\hline No & Parameter & Bobot & Kelas & Faktor & Penilaian \\
\hline \multirow[t]{5}{*}{1} & \multirow{5}{*}{$\begin{array}{l}\text { Tutupan vegetasi } \\
\text { (Vegetation cover) }\end{array}$} & \multirow[t]{5}{*}{7} & Savanna (Sangat kering) & 5 & Sangat tinggi \\
\hline & & & Hutan Pantai dan Hutan Musim (Kering) & 4 & Tinggi \\
\hline & & & Hutan Dataran Rendah (Lembab) & 3 & Sedang \\
\hline & & & Mangrove (Agak basah) & 2 & Rendah \\
\hline & & & Perairan (Basah) & 1 & Sangat Rendah \\
\hline \multirow[t]{5}{*}{2} & \multirow[t]{5}{*}{ Lereng (Slope) } & \multirow[t]{5}{*}{ 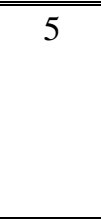 } & $>35 \%$ & 5 & Sangat tinggi \\
\hline & & & $25-35 \%$ & 4 & Tinggi \\
\hline & & & $10-25 \%$ & 3 & Sedang \\
\hline & & & $5-10 \%$ & 2 & Rendah \\
\hline & & & $<5 \%$ & 1 & Sangat Rendah \\
\hline \multirow[t]{4}{*}{3} & \multirow{4}{*}{$\begin{array}{l}\text { Orientasi/arah } \\
\text { lereng } \\
(\text { Aspect })\end{array}$} & \multirow[t]{4}{*}{5} & Selatan & 5 & Sangat tinggi \\
\hline & & & Barat & 4 & Tinggi \\
\hline & & & Timur & 3 & Sedang \\
\hline & & & Utara & 2 & Rendah \\
\hline \multirow[t]{5}{*}{4} & \multirow{5}{*}{$\begin{array}{l}\text { Jarak dari jalan } \\
\text { (Distance from } \\
\text { road) }\end{array}$} & \multirow[t]{5}{*}{3} & $<100 \mathrm{~m}$ & 5 & Sangat tinggi \\
\hline & & & $100-200 \mathrm{~m}$ & 4 & Tinggi \\
\hline & & & $200-300 \mathrm{~m}$ & 3 & Sedang \\
\hline & & & $300-400 \mathrm{~m}$ & 2 & Rendah \\
\hline & & & $>400 \mathrm{~m}$ & 1 & Sangat Rendah \\
\hline \multirow[t]{4}{*}{$\overline{5}$} & \multirow{4}{*}{$\begin{array}{l}\text { Jarak dari } \\
\text { permukiman } \\
\text { (Distance from } \\
\text { settlements) }\end{array}$} & \multirow[t]{4}{*}{3} & < $<1000 \mathrm{~m}$ & 5 & "Sangat tinggi \\
\hline & & & $1000-2000 \mathrm{~m}$ & 4 & Tinggi \\
\hline & & & $2000-3000 \mathrm{~m}$ & 3 & Sedang \\
\hline & & & $>3000 \mathrm{~m}$ & 2 & Rendah \\
\hline
\end{tabular}

Sumber : (Erten et al, 2004)

2. Overlay peta

Pada tahap ini Peta Kelas setiap parameter penentu tingkat kerawanan kebakaran hutan dioverlay sehingga dihasilkan satu peta baru. Peta tersebut dimodifikasi tabel atributnya dengan menambahkan dua kolom terdiri dari kolom RC (nilai indeks numerik zonasi kebakaran hutan) dan kolom tingkat rawan.

Kelas bahaya kebakaran hutan dan lahan ditentukan oleh penjumlahan dari semua nilai/bobot faktor-faktor (elemen) dalam suatu analisis tumpang susun.
Penentuan interval kelas untuk menentukan kelas rawan digunakan rumus Sturges.

Penyusunan dengan kisaran tingkat bahaya kebakarannya adalah sebagai berikut:

\section{Interval kelas $=\quad$ Range \\ Banyak kelas}

Keterangan:

Range $=$ kelas tertinggi dikurangi kelas terendah

Tabel 2 digunakan untuk menentukan tingkat kerawanan kebakaran hutan. 
Tabel 2. Indeks Numerik Tingkat Rawan sehingga pada akhirnya memudahkan Kebakaran Hutan

\begin{tabular}{clc}
\hline No & RC & Tingkat Rawan \\
\hline \hline 1 & $>97$ & Sangat Tinggi \\
2 & $>81-97$ & Tinggi \\
3 & $>65-81$ & Sedang \\
4 & $>49-65$ & Rendah \\
5 & $<49$ & Sangat Rendah \\
\hline \hline
\end{tabular}

Untuk menghitung besarnya nilai

$\mathrm{RC}$ digunakan persamaan berikut:

$\mathrm{RC}=7 * \mathrm{VT}+5 *(\mathrm{~S}+\mathrm{A})+3 *(\mathrm{DR}+\mathrm{DS})$

dimana:

$\mathrm{RC}=$ Indeks numerik tingkat rawan

kebakaran hutan

$\mathrm{VT}=$ Tipe vegetasi

$\mathrm{S}=$ Kemiringan

$\mathrm{A}=$ Aspek

$\mathrm{DR}=$ Jarak dari jalan

$\mathrm{DS}=$ Jarak dari permukiman

(Erten et al, 2004)

3. Dissolve

Dissolve secara bahasa berarti menghancurkan. Makna ini sesuai dengan maksud dari bahasa program Arc GIS, dimana dissolve digunakan untuk menyatukan poligon-poligon kecil yang memiliki kriteria sama dan berhimpit satu sama lain sehingga menjadi polygon besar dengan menghancurkan / menghilangkan garis-garis sekatnya. Hasil dari dissolve ini tampak juga pada atribut tabel dimana jumlah fid disederhanakan menjadi sama banyak jumlah criteria yang didissolve tinggi karena memiliki tutupan lahan berupa hutan lahan sekunder, pertanian

\section{Pembuatan Layout Peta}

Layout peta merupakan hasil akhir dari semua proses pembuatan peta zonasi tingkat rawan kebakaran hutan yang dilengkapi dengan semua atribut yang memudahkan peta tersebut dibaca. Contoh atribut peta yang dimaksud adalah judul peta, arah mata angin, skala, legenda, tim penyusun, dan tahun pembuatan.

\section{HASIL DAN PEMBAHASAN}

\section{Sebaran Daerah Rawan Kebakaran Hutan dan Lahan}

Sebaran wilayah yang memiliki potensi rawan kebakaran hutan dan lahan yang sangat tinggi di kabupaten Gowa berada di kecamatan Parangloe, Tombolopao, Bungaya, Bontolempangan, Biringbulu, Manuju dan Pattallassang. Luasan daerah rawan kebakaran hutan dan lahan di 7 (tujuh) Kecamatan ini seluas $1.735,42 \mathrm{Ha}$ atau sebesar $0,96 \%$ dari total luas wilayah Kabupaten Gowa. Daerah ini memiliki tingkat kerawanan terhadap kebakaran hutan dan lahan yang sangat

lahan kering campur semak, semak belukar dan memiliki tingkat kemiringan 
$>35 \%$. Arah lereng menghadap ke maka hutan semakin terhindar dari selatan dan barat (memiliki intensitas kebakaran (Arianti, 2006).

penyinaran yang lama), jarak akses dari

Wilayah dengan kerawanan

pemukiman < $1000 \mathrm{~m}$, jarak akses dari kebakaran kelas tingkat kerawanan rendah jalan $<100$ m dan $100-200$ m. Jarak dari tersebar diseluruh wilayah kabupaten jaringan jalan, pemukiman penduduk Gowa. Hal ini dikarenakan pada wilayah memiliki peranan sangat penting bagi ini memilikitutupan lahan berupa hutan aktivitas manusia, sehingga jalan dan lahan sekunder, pertanian lahan kering pemukiman penduduk merupakan faktor campur semak, sawah, lahan terbuaka, penyebab kebakaran hutan dan lahan. hutan tanaman dan semak belukar Semakin jauh lokasi hutan terhadap memiliki namun memiliki akses dari jalan pemukiman penduduk, jalan, dan sungai $300-400 \mathrm{~m}$ dan akses dari pemukiman > $3000 \mathrm{~m}$.

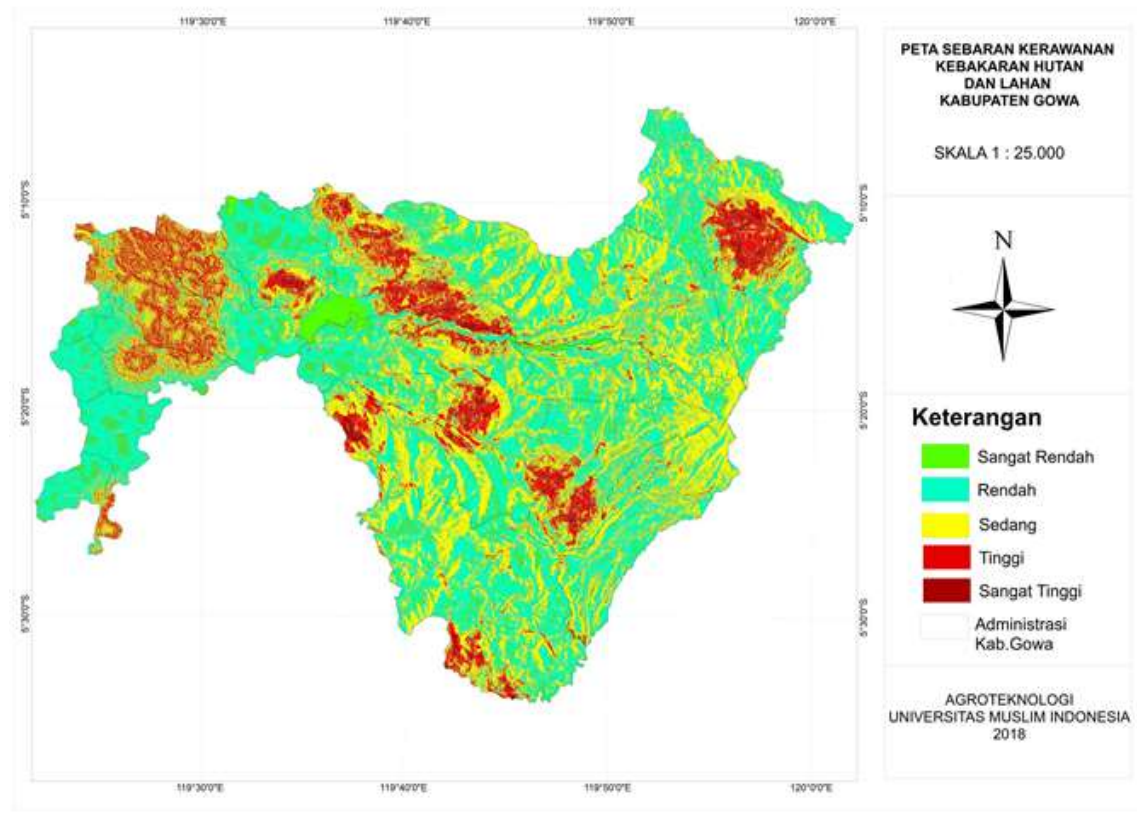

Gambar 1. Peta Sebaran Kerawanan Kebakaran Hutan dan Lahan Kabupaten Gowa 
Yuliandri Pualilin : Pemetaan Zonasi Daerah Rawan Kebakaran Hutan dan Lahan di Kabupaten Gowa

Tabel 3. Sebaran Daerah Rawan Kebakaran Hutan dan Lahan di Kabupaten Gowa

\begin{tabular}{|c|c|c|c|c|c|c|}
\hline \multicolumn{7}{|c|}{ S Sebaran Kebakaran Hutan Lahan Berdasarkan Kelas Rawan Kebakaran } \\
\hline Kecamatan & Rendah & $\begin{array}{l}\text { Sangat } \\
\text { Rendah }\end{array}$ & $\begin{array}{l}\text { Sangat } \\
\text { Tinggi }\end{array}$ & Sedang & Tinggi & Luas (Ha) \\
\hline Bajeng & 1795.46 & 217.42 & 4.00 & 2374.19 & 763.23 & 5154.31 \\
\hline Bajeng Barat & 1592.20 & 298.67 & & 67.86 & 0.33 & 1959.06 \\
\hline Barombong & 881.08 & 169.48 & 2.47 & 981.75 & 352.11 & 2386.89 \\
\hline Biringbulu & 10697.47 & 1821.45 & 123.45 & 8846.11 & 1027.74 & 22516.21 \\
\hline Bontolempangan & 4395.92 & 567.81 & 187.44 & 5122.81 & 1391.12 & 11665.09 \\
\hline Bontomarannu & 2653.49 & 564.88 & 1.72 & 1705.11 & 573.46 & 5498.66 \\
\hline Bontonompo & 3010.25 & 828.44 & 0.02 & 154.68 & 22.94 & 4016.33 \\
\hline Bontonompo selatan & 1652.16 & 502.64 & 0.70 & 597.31 & 238.58 & 2991.39 \\
\hline Bungaya & 6122.05 & 887.81 & 379.95 & 8687.61 & 2242.52 & 18319.94 \\
\hline Manuju & 4632.81 & 1214.69 & 61.46 & 4385.07 & 985.64 & 11279.67 \\
\hline Pallangga & 221.10 & 0.24 & 9.14 & 3075.75 & 2251.03 & 5557.26 \\
\hline Parangloe & 5420.11 & 1984.53 & 447.95 & 8333.79 & 3647.79 & 19834.17 \\
\hline Parigi & 3622.80 & 682.48 & & 3889.56 & 79.51 & 8274.35 \\
\hline Pattallassang & 3993.52 & 1367.90 & 125.82 & 1756.54 & 584.49 & 7828.27 \\
\hline Sombaopu & 39.52 & & 4.06 & 1363.63 & 1514.31 & 2921.52 \\
\hline Tinggimoncong & 7114.76 & 791.94 & & 8549.89 & 285.96 & 16742.55 \\
\hline Tombolopao & 9161.88 & 1575.18 & 409.34 & 7482.37 & 2594.59 & 21223.36 \\
\hline Tompobulu & 5327.00 & 495.57 & & 6260.90 & 166.75 & 12250.23 \\
\hline Luas total (ha) & 72333.60 & 13971.12 & 1757.53 & 73634.92 & 18722.10 & 180419.27 \\
\hline
\end{tabular}

Sumber : Pengolahan Data

Zonasi Kerawanan Kebakaran Hutan dan Lahan di Kabupaten Gowa

Berdasarkan hasil analisis data dan pemetaan Kabupaten Gowa merupakan wilayah yang didominasi oleh tingkat bahaya kebakaran kelas kerawanan rendah sampai sedang dengan luas masingmasing $68.777,43$ ha dan $70.132,79$ ha atau persentase sebesar $38,12 \%$ dan $38,87 \%$ sedangkan kelas kerawanan tinggi seluas 23.287,96 ha atau sebesar 12,90\%, kelas kerawanan sangat rendah seluas $15.251,76$ ha atau persentase sebesar 8,45 $\%$ dan kelas kerawanan sangat tinggi seluas 2.969.31 ha atau persentase sebesar 1,64\%. Hal ini dapat dilihat pada peta rawan kebakaran hutan dan lahan yang disajikan pada Gambar 2 .

Berdasarkan analisis spasial terhadap penutupan lahan, ternyata penutupanlahan/vegetasi Belukar, Sawah dan Pertanian Lahan Kering Sekunder merupakan vegetasi yang paling peka terhadap bahaya kebakaran dibanding jenis penutupan lahan lainnya, hal ini karena jenis penutupan lahan tersebut mengandung banyak bahan bakar ringan dan umumnya relatif kering karena kelembaban lingkungannya rendah. Menurut Anderson et al., (1999) dalam Sabaradji (2005) bahwa jenis vegetasi 
padang rumput dan semak belukar tingkat bahaya kebakarannya sangat tinggi.

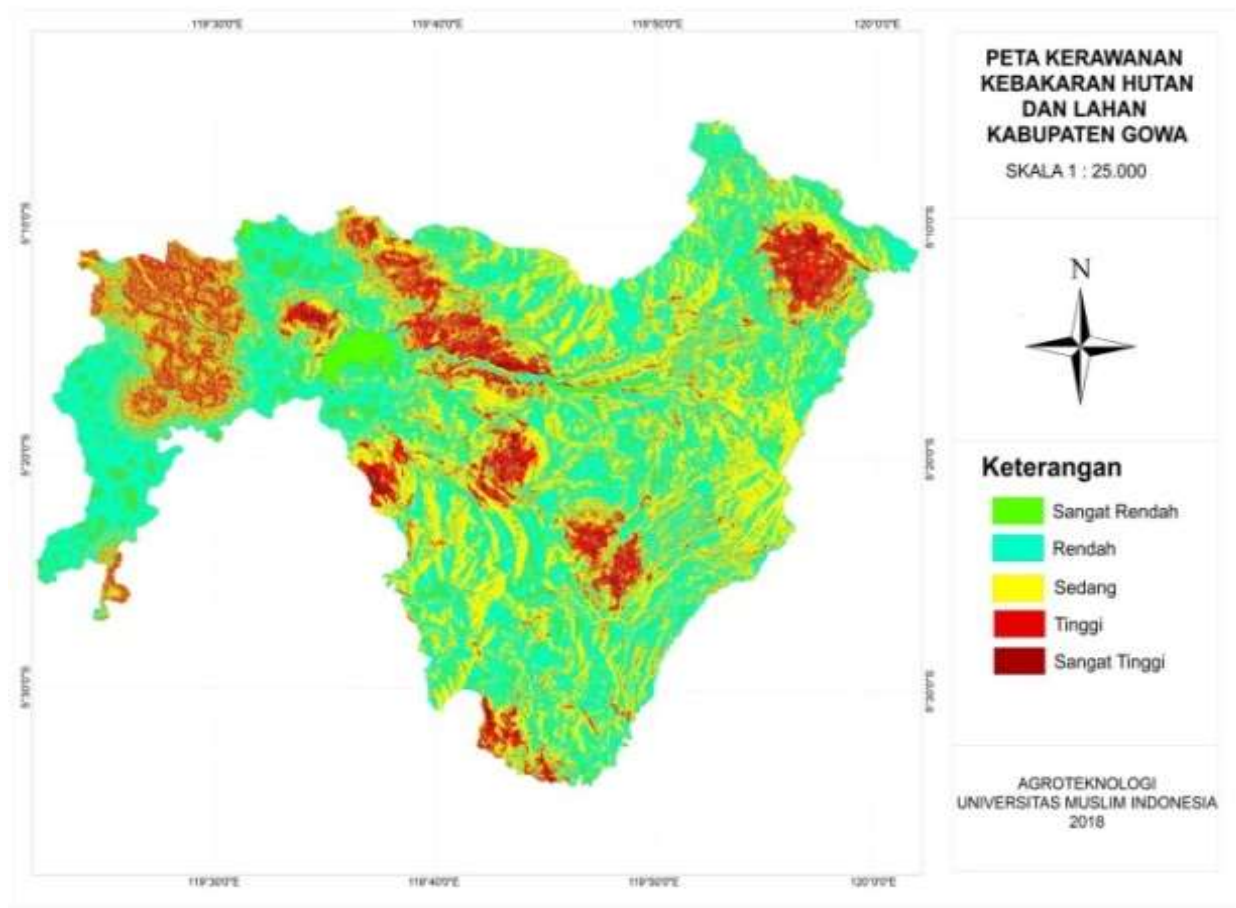

Gambar 2. Peta Kerawanan Kebakaran Hutan dan Lahan Kabupaten Gowa

Berdasarkan analisis spasial padang rumput dan semak belukar tingkat terhadap penutupan lahan,ternyata bahaya kebakarannya sangat tinggi.

penutupanlahan/vegetasi Belukar, Sawah

Perbedaan kelas rawan kebakaran dan Pertanian Lahan Kering Sekunder hutan dan lahan yang terjadi pada merupakan vegetasi yang paling peka seluruh kecamatan di Kabupaten Gowa terhadap bahaya kebakaran dibanding tidak hanya dapat dilihat pada satu jenis penutupan lahan lainnya, hal ini parameter (faktor penyebab kebakaran karena jenis penutupan lahan tersebut hutan dan lahan) saja, karena semua mengandung banyak bahan bakar ringan parameter akan saling mempengaruhi dan umumnya relatif kering karena terjadinya kebakaran hutan dan lahan kelembaban lingkungannya rendah. Validasi peta kerawanan kebakaran Menurut Anderson et al., (1999) dalam hutan di Kabupaten Gowa dilakukan Sabaradji (2005) bahwa jenis vegetasi dengan membandingkan hasil analisis dengan kejadian kebakaran yang pernah 
terjadi di Kabupaten Gowa. Hasil validasi menunjukkan bahwa dari 34 lokasi titik kebakaran yang pernah terjadi, sebanyak 32 titik lokasi kejadian kebakaran hutan di Kabupaten Gowa terjadi pada kelas kerawanan tinggi sampai sangat tinggi, sedangkan 2 titik kebakaran berada pada kelas kerawanan Sedang.

Beberapa wilayah dengan kelas kerawanan tinggi seperti pada wilayah kecamatan Tompobulu, Biringbulu, Manuju dan Tinggimoncong pernah mengalami kebakaran namun tidak terjadi setiap tahun. Kelas kerawanan sangat tinggi terhadap kebakaran hutan dan lahan pada pada wilayah kecamatan Parangloe berdasarkan data laporan kejadian kebakaran memiliki catatan frekuensi kebakaran berturut -turut 2017 sebanyak 3 kali dan 2018 sebanyak 5 kali. Hal ini dikarenakan tutupan vegetasi pada wilayah tersebut didominasi lahan pertanian dan semak belukar. Tipe kebakaran yang terjadi di kabupaten gowa termasuk kebakaran permukaan. Menurut De Bano et al., (1998), pada kebakaran permukaan api membakar serasah, tumbuhan bawah, bekas limbah pembakaran dan bahan bakar lainya yang terdapat di lantai hutan
Beberapa wilayah dengan kelas kerawanan tinggi seperti pada wilayah kecamatan Tompobulu, Biringbulu, Manuju dan Tinggimoncong pernah mengalami kebakaran namun tidak terjadi setiap tahun. Kelas kerawanan sangat tinggi terhadap kebakaran hutan dan lahan pada pada wilayah kecamatan Parangloe berdasarkan data laporan kejadian kebakaran memiliki catatan frekuensi kebakaran berturut-turut 2017 sebanyak 3 kali dan 2018 sebanyak 5 kali. Hal ini dikarenakan tutupan vegetasi pada wilayah tersebut didominasi lahan pertanian dan semak belukar. Tipe kebakaran yang terjadi di kabupaten gowa termasuk kebakaran permukaan. Menurut De Bano et al., (1998), pada kebakaran permukaan api membakar serasah, tumbuhan bawah, bekas limbah pembakaran dan bahan bakar lainya yang terdapat di lantai hutan.

\section{KESIMPULAN}

1. Faktor yang berpotensi menyebabkan kebakaran hutan dan lahan di Kabupaten Gowa yaitu tutupan lahan (pertanian lahan kering, hutan lahan kering sekunder, dan semak belukar);

2. Wilayah rawan kebakaran hutan dan lahan yang paling berpotensi terjadi di 
Kecamatan Parangloe, Tombolopao, Bungaya, Bontolempangan,

Biringbulu, Manuju dan Pattallassang dengan total luas $1.735,42$ ha atau sebesar $0,96 \%$ dari total luas wilayah Kabupaten Gowa. Sedangkan daerah rawan kebakaran hutan dan lahan yang berfotensi kecil terjadi di Kecamatan Pallangga dengan luas 0,24 ha.

3. Zonasi tingkat kerawanan kebakaran hutan dan lahan di kabupaten Gowa dapat terbagi kedalam lima kelas yaitu zona tidak rawan (sangat rendah), zona rendah, sedang, tinggi dan sangat rawan, Zona bahaya kebakaran hutan dan lahan terluas yaitu pada zona rendah sampai sedang dengan luas masing masing $68.777,43$ ha dan $70.132,79$ ha.

\section{DAFTAR PUSTAKA}

Arianti I. 2006. Pemodelan Tingkat dan Zona Kerawanan Kebakaran Hutan dan Lahan Menggunakan Sistem Informasi Geografis Di Sub Das Kapuas Tengah, Propinsi Kalimantan Barat [tesis]. Bogor: Institut Pertanian Bogor.

De Bano, L.F., D.G. Neary and P.F. Ffolliott. 1998. Fire's Effects on Ecosystems. New York: John Wiley\& Sons, Inc. 333 p.

Rianawati, F., Asari, M., Asysyfa. 2016. Pemetaan Daerah Rawan Kebakaran Pada Lahan Basah di Kecamatan Gambut Provinsi Kalimantan Selatan. Prosiding Seminar Nasional dan Gelar Produk, Hal. 71 - 80.

Sabaraji, A, 2005. Identifikasi Zone Rawan Kebakaran Hutan dan Lahan dengan Aplikasi SIG di Kabupaten Kutai Timur. Universitas Mulawarman. Samarinda.

Samsuri, S., Jaya, I. N. S., \& Syaufina, L. 2012. Model Spasial Tingkat Kerawanan Kebakaran Hutan dan Lahan (Studi Kasus Propinsi Kalimantan Tengah). Foresta Indonesia Journal of Forestry, (1), $12-18$. 